\title{
The expression of calpain 1 and calpain 2 in spermatogenic cells and spermatozoa of the mouse
}

\author{
Irit Ben-Aharon, Paula R Brown ${ }^{1}$, Nir Etkovitz ${ }^{2}$, Edward M Eddy ${ }^{1}$ and Ruth Shalgi \\ Department of Cell and Developmental Biology, Sackler School of Medicine, Tel-Aviv University, Tel-Aviv, Israel, \\ ${ }^{1}$ Gamete Biology Section, Laboratory of Reproductive and Developmental Toxicology, National Institute of \\ Environmental Health Sciences, National Institutes of Health, Research Triangle Park, North Carolina, USA \\ and ${ }^{2}$ Faculty of Life Sciences, Bar-Ilan University, Ramat-Gan, Israel \\ Correspondence should be addressed to R Shalgi; Email: shalgir@post.tau.ac.il
}

\begin{abstract}
There is some evidence suggesting that $\mathrm{Ca}^{2+}$ is involved in processes that occur during the development and function of spermatozoa. Calcium-dependent proteins, such as calmodulin, are expressed during mammalian spermatogenesis further suggesting that $\mathrm{Ca}^{2+}$ takes part in its regulation. However, the precise roles of $\mathrm{Ca}^{2+}$ in spermatogenesis remain to be elucidated. Calpains are a family of $\mathrm{Ca}^{2+}$-dependent cysteine proteases whose members are expressed ubiquitously or in a tissue-specific manner. Calpain has been demonstrated to mediate specific $\mathrm{Ca}^{2+}$-dependent processes including cell fusion, mitosis and meiosis. We herein followed the expression pattern of calpain's ubiquitous isoforms, 1 and 2, throughout spermatogenesis at the RNA and protein levels by RT-PCR and Western blotting analysis. Both RNA and protein studies revealed that these isoforms are expressed in all spermatogenic cells. The expression of calpain 1 levels is slightly higher in spermatocytes entering the meiotic phase. Both calpain isoforms are also expressed in mouse spermatozoa and are localized to the acrosomal cap. Inducing capacitated spermatozoa to undergo the acrosome reaction in the presence of a selective calpain inhibitor significantly reduced the acrosome reaction rate in a dose-dependent manner. Thus, calpain, a pluripotential protease with numerous substrates, may serve as an effector in more than one pathway in the complex process of spermatogenesis and in the events preceding fertilization, such as the acrosome reaction.

Reproduction (2005) 129 435-442
\end{abstract}

\section{Introduction}

Calcium has been shown to play a pivotal role in processes that occur during the development and function of spermatozoa. Spermatogenesis involves a series of mitotic divisions by spermatogonia that give rise to spermatocytes, and a pair of meiotic divisions by spermatocytes to yield the spermatids. Transient increases in intracellular $\mathrm{Ca}^{2+}$ concentration serve as a key signal for the initiation and termination of mitosis in somatic cells (Whitaker \& Patel 1990) and the resumption of meiosis in mammalian oocytes (Kline \& Kline 1992, Berrios et al. 1998). Spermatogenic cells are known to possess a variety of $\mathrm{Ca}^{2+}$ channels (Hagiwara \& Kawa 1984). Changes in $\mathrm{Ca}^{2+}$ concentrations in spermatogenetic cells in response to alkalinization have been reported (Santi et al. 1998) and it has been demonstrated that $\mathrm{Ca}^{2+}$ signaling occurs in round spermatids (Berrios et al. 1998). Moreover, calciumdependent proteins, such as calmodulin, are present during mammalian spermatogenesis (Slaughter et al. 1989, Watanabe et al. 1994), further suggesting that $\mathrm{Ca}^{2+}$ is involved in the regulation of spermatogenesis. However, the precise roles of $\mathrm{Ca}^{2+}$ in spermatogenesis remain to be elucidated.

Binding of spermatozoa to the zona pellucida (ZP) during fertilization activates a G-protein-coupled signaling pathway. This triggers a $\mathrm{Ca}^{2+}$ influx and leads to an increase in the intracellular $\mathrm{Ca}^{2+}$ concentration that induces the acrosome reaction (AR), enabling the spermatozoon to penetrate the ZP and fertilize the egg (Bailey \& Storey 1994, Abou-Haila \& Tulsiani 2000). Furthermore, $\mathrm{Ca}^{2+}$-mediated signaling leads to fusion of the spermatozoon plasma membrane with the oolemma (Yanagimachi 1989).

Calpains constitute a superfamily of intracellular calcium-dependent neutral cysteine proteases whose members are widely expressed in a variety of tissues and cells (Murachi et al. 1981, Sorimachi et al. 1993a,b, Carafoli \& Molinari 1989). Two ubiquitous members of the calpain family, calpain 1 (CANP1) and calpain 2 (CANP2), have been well characterized in many cells. They are the large 
catalytic subunits $(80 \mathrm{kDa})$ that heterodimerize with calpain 4 , the small regulatory subunit $(30 \mathrm{kDa})$ of the holoenzyme. However, they differ considerably in the calcium concentrations required for their activation in vitro. Calpain 1 ( $\mu$ calpain) is activated at micromolar calcium concentrations and calpain 2 (m calpain) at millimolar concentrations (Croall \& Demartino 1991, Sorimachi et al. 1994). The need for calpain in normal development has been demonstrated in transgenic mice lacking the calpain 4 regulatory subunit. These mice die during embryonic development apparently due to defects in vascular development (Arthur et al. 2000, Perrin \& Huttenlocher 2002). The non-ubiquitous tissue-specific calpains are most likely related to the specific functions of the organs in which they are predominantly expressed.

Calpains have been implicated in diverse cellular signaling pathways mediated by calcium. These include cytoskeleton remodeling, cell cycle regulation, cell differentiation and membrane fusion (Croall \& Demartino 1991, Carafoli \& Molinari 1998, Barnoy et al. 1999). Calpains also participate in several phases of mitosis and meiosis (Schollmeyer 1988, Lane et al. 1992, Santella et al. 1998). They are suggested to play a role in regulating meiosis by inactivating c-mos proto-oncogene product, pp39, hence leading to resumption of the second meiosis in MII-arrested Xenopus eggs (Sagata et al. 1989, Watanabe et al. 1989). Injection of calpain into the nuclei of prophase-arrested starfish oocytes induced re-initiation of meiosis by mediating cytoskeletal remodeling (Santella et al. 1998, 2000). In the rat egg, we demonstrated a correlation between calpain activation and egg activation at fertilization, where inhibiting calpain activity impeded resumption of meiosis (I Ben-Aharon, K Haim, R Shalgi and D Ben-Yosef, unpublished observations).

In mammals, calpain 2 was localized to the acrosomal cap of porcine sperm (Schollmeyer 1986), and Rojas et al. (1999) demonstrated the presence of a calpain-calpastatin system in human spermatozoa. Both isoforms are expressed in spermatozoa of the Cynomolgus macaque, and ultrastructural studies indicated they were localized between the plasma membrane and the outer acrosomal membrane (Yudin et al. 2000). Calpain inhibitors used during in vitro fertilization impaired the ability of human sperm to fuse and penetrate the oocyte (Rojas \& MorretiRojas 2000). The putative role of calpain in human spermatozoa prior to and during fertilization along with its possible involvement throughout meiosis in eggs had prompted us to examine further the expression of calpain ubiquitous isoforms in the spermatogenic germ line in the mouse. We have demonstrated the expression of both mRNA and protein during spermatogenesis, and localized calpain 1 and calpain 2 in mouse spermatozoa. To further elucidate calpain's possible role in spermatozoa, we introduced capacitated spermatozoa to a highly selective calpain inhibitor, calpeptin, and found a dose-dependent reduction in acrosome reaction rate.

\section{Materials and Methods}

\section{Tissue collection}

\section{Spermatozoa}

Cauda epididymides from 10-week-old C57BL/6 mice were punctured and the spermatozoa were collected into an ice-cold buffer containing $20 \mathrm{mM}$ Tris, $130 \mathrm{mM} \mathrm{NaCl}$, 2 mM EGTA, pH 7.15 (TN/EGTA; Kalab et al. 1994). Spermatozoa were centrifuged at $1000 \mathrm{rpm}$ for $10 \mathrm{~min}\left(4^{\circ} \mathrm{C}\right)$ and the pellet was then re-suspended in TN/EGTA buffer. Aliquots containing $1 \times 10^{6}$ spermatozoa were stored at $-70^{\circ} \mathrm{C}$ until use.

\section{Spermatogenic cells}

To obtain enriched populations of certain spermatogenic cell types we have employed the method developed by Bellvé et al. (1977a) for RNA and protein studies by harvesting testes at specific time points throughout the first wave of spermatogenesis. The first wave of spermatogenesis in the mouse is from day 10 to day 30 after birth. Testes were therefore collected from 6- to 30-day-old CD1 mice and crude protein extracts were isolated by homogenizing in lysis buffer (20 mM HEPES pH 7.4, $140 \mathrm{mM}$ $\mathrm{NaCl}, 0.1 \%$ Triton X-100, and Complete Proteinase Inhibitor cocktail (Roche Diagnostics, Basel, Switzerland) at a concentration of $50 \mathrm{mg}$ (wet weight)/ml. All animal procedures were approved by the Tel-Aviv University and the National Institute of Environmental Health Sciences Animal Care and Use Committees before being used.

\section{Immunoblotting procedures}

Aliquots of spermatozoa or spermatogenic cell lysates corresponding to $0.5 \mathrm{mg}$ (wet weight) were mixed with Laemmli buffer (New England BioLabs, Beverly, MA, USA) and boiled for $5 \mathrm{~min}$. Proteins were fractionated by onedimensional sodium dodecyl sulfate- polyacrylamide gel electrophoresis (SDS-PAGE) on a $10 \%$ gels at $30 \mathrm{~mA}$ per gel in $25 \mathrm{mM}$ Tris, $192 \mathrm{mM}$ glycine and $0.1 \%$ SDS (Laemmli 1970). Gels were electro-transferred overnight onto nitrocellulose membranes (Amersham, UK) or ImobiIon nylon membranes (Millipore Corp., Bedford, MA, USA) at $40 \mathrm{~mA}$ in $25 \mathrm{mM}$ Tris, $192 \mathrm{mM}$ glycine and $20 \%$ methanol transfer buffer (Towbin et al. 1979). Approximate molecular masses were determined by comparison with the migration of prestained protein standards (Amersham, UK or BioRad, Hercules, CA, USA). Blots were blocked in $150 \mathrm{mM} \mathrm{NaCl}, 10 \mathrm{mM}$ Tris, $0.5 \%$ Tween 20 (TBS/Tween) and $5 \%$ nonfat dry milk (referred to as 'blocking solution') for $2 \mathrm{~h}$ at room temperature. Membranes were then incubated for $18 \mathrm{~h}$ at $4{ }^{\circ} \mathrm{C}$ with either a monoclonal antibody to calpain 1 (208728; Calbiochem, San Diego, CA, USA) diluted 1:100 in blocking solution, or a monoclonal antibody to calpain 2 (208729; Calbiochem) diluted 1:500 in blocking solution. These antibodies were also used in the immunofluorescence and 
immunoblotting procedures described below. Following 3 washes in blocking solution, blots were incubated for $1 \mathrm{~h}$ in donkey anti-mouse $\operatorname{lgG}$ antibody conjugated to horseradish peroxidase (Jackson, Immunoresearch Laboratories, West Grove, PA, USA) diluted 1:5000 in blocking solution. The blots were washed in TBS/Tween solution and proteins detected using the Supersignal chemiluminescence detection system (Pierce, Rockford, IL, USA) and autoradiographed. Each set of experiments was repeated at least three times.

\section{Immunofluorescence procedures}

Spermatozoa collected from the cauda epididymides of 10-week-old C57BL/6 mice were suspended in Dulbecco's phosphate buffered saline (DPBS) supplemented with 3\% fetal calf serum. Cells were permeabilized by slowly dripping pellets along the side of a test-tube immersed in ice. Samples were warmed to room temperature and the procedure was then repeated (Jones et al. 1983). Permeabilized spermatozoa were incubated for $2 \mathrm{~h}$ in the presence of monoclonal antibodies (diluted 1:75) to calpain 1 and calpain 2 and washed three times in blocking solution. Samples were then transferred into blocking solution containing Cy3-labeled donkey antibody to mouse $\lg \mathrm{G}(1: 500)$ and $1 \mu \mathrm{g} / \mathrm{ml}$ of a DNA-specific fluorochrome (Hoechst 33342; Sigma) for a further 30 min incubation in the dark. Spermatozoa were washed 3 times in blocking solution, and then mounted between a slide and a coverslip.

Spermatozoa were visualized and photographed using a $40 \times$ NA/1.2 planapochromat water immersion lens with a Zeiss (Oberkochen, Germany) LSM 410 confocal laser scanning microscope (CLSM) equipped with a $25-\mathrm{mW}$ Krypton-Argon laser, a 10-mW helium-neon laser (488, 543 and 633 maximum lines), and a UV laser (Coherent Inc. Laser Group, Santa Clara, CA, USA). For localization of either calpain, spermatozoa were scanned using the CLSM through the Z-axis to select a section at the equatorial plane of the spermatozoon. Data was obtained from visualizing 6 representative spermatozoa in each experiment. Each set of experiments was repeated at least three times.

\section{Immunohistochemical procedures}

Testes from juvenile and adult CD-1 mice were fixed in Bouin's solution, paraffin embedded, and sections were mounted on Superfrost/Plus slides (Daigger and Co., Wheeling, IL, USA). Deparaffinized sections were treated with $3 \% \mathrm{H}_{2} \mathrm{O}_{2}$ to inactivate endogenous peroxidase, blocked for $1 \mathrm{~h}$ with MOM blocking reagent (Vector Labs, Burlingame, CA, USA), and then incubated with antibodies to calpain 1 or calpain 2 (1:300 in diluent reagent, Vector Labs) for $30 \mathrm{~min}$. Negative controls were incubated with diluent only. Slides were then incubated with biotinylated anti-mouse $\operatorname{lgG}$ in diluent $(1: 250$, Vector) for $30 \mathrm{~min}$, followed by $A B C$ reagent (Vector) for $30 \mathrm{~min}$, and rinsed in water. The peroxidase activity was visualized after exposing slides to diaminobenzidine (DAB; Sigma) for $5 \mathrm{~min}$. Slides were rinsed with TBS and coverslips were mounted with glycerol. Each set of experiments was repeated at least three times.

\section{Semi-quantitative reverse transcriptase PCR (RT-PCR)}

Primers specific for mouse Canp1, Canp2, and $\beta$-actin were designed (Table 1). Total RNA was extracted with TRIzol Reagent (Invitrogen, Carlsbad, CA, USA) from testes collected on postnatal days 6 through 34 . The RNA $(2 \mu \mathrm{g})$ was treated with amplification grade DNase I (Invitrogen) prior to addition of $200 \mathrm{U}$ SuperScript II RNase $\mathrm{H}^{-}$reverse transcriptase (Invitrogen) according to the supplier's recommendations. The RT products $(1 \mu \mathrm{l})$ were then used as PCR templates. The PCR cycle parameters were $30 \mathrm{~s}$ at $94^{\circ} \mathrm{C}$, then $20 \mathrm{~s}$ at $94^{\circ} \mathrm{C}, 20 \mathrm{~s}$ at $58^{\circ} \mathrm{C}$, and $20 \mathrm{~s}$ at $72^{\circ} \mathrm{C}$ for 30 cycles using AmpliTAQ polymerase. These reactions were repeated three times and the average concentration $(\mathrm{ng} / \mu \mathrm{l})$ determined (see Fig. 3). Samples were analyzed using an Agilent 2100 Bioanalyzer (Agilent Technologies, Palo Alto, CA, USA), a microfluidic system using microfabricated chip technology. This method normalizes the mean values obtained for calpain isoforms for each age group by using $\beta$-actin values as standard, and depicts a densitometric presentation for the results.

\section{Effect of calpain inhibitor on the acrosome reaction}

Cauda epididymides and part of the vas-deferens were collected from 10-week-old C57BL/6 mice, and minced in $1 \mathrm{ml}$ modified Krebs-Ringer bicarbonate medium (HM; Visconti et al. 1995). Spermatozoa were discharged from the epididymal lumen for $15 \mathrm{~min}$ at $37^{\circ} \mathrm{C}$, washed, and left for 'swim-up' for an additional $20 \mathrm{~min}$ at $37^{\circ} \mathrm{C}$. Spermatozoa were collected, counted and resuspended $\left(10^{6} \mathrm{cell} / \mathrm{s} / \mathrm{ml}\right)$ in capacitation medium (HMB; Visconti et al. 1995) for $1.5 \mathrm{~h}$ at $37^{\circ} \mathrm{C} ; 5 \% \mathrm{CO}_{2}$ in air. Spermatozoa were incubated in the presence of the calpain inhibitor, calpeptin (03340051; Calbiochem) for $10 \mathrm{~min}$. Spermatozoa were then exposed to $10 \mu \mathrm{M} \mathrm{Ca}^{2+}$ ionophore (A23187; Calbiochem), for the induction of the acrosome reaction, for $20 \mathrm{~min}$ in the presence of calpeptin. An aliquot of spermatozoa $\left(10^{6}\right.$ cells $)$ was smeared on a glass slide and allowed to air dry. Spermatozoa were then permeabilized by methanol for $15 \mathrm{~min}$ at room temperature, washed three times at 5 -min intervals with $25 \mathrm{mM}$ Tris-buffered saline $\mathrm{pH} 7.6$ (TBS) and air dried. FITC-conjugated Pisum sativum agglutinin (PSA;

Table 1 Primers specific for calpain 1, calpain 2 and $\beta$-actin.

\begin{tabular}{|c|c|c|c|}
\hline Primer & & cDNA (bp) & Genomic (bp) \\
\hline Calpain 1 & $\begin{array}{l}5^{\prime} \text { cggttggaggaggtggatga } \\
3^{\prime} \text { atcacgcttcaagtgcacag }\end{array}$ & 189 & $\sim 2980$ \\
\hline Calpain 2 & $\begin{array}{l}5^{\prime} \text { caccctcacctgtgactcctataa } \\
3^{\prime} \text { atcctcctcatcttcgtctt }\end{array}$ & 163 & $\sim 2310$ \\
\hline $\begin{array}{l}\text { Mouse } \\
\beta \text {-actin }\end{array}$ & $\begin{array}{l}5^{\prime} \text { ttccgatgccctgaggctctttc } \\
3^{\prime} \text { cttgctgatccacatctgctggaa }\end{array}$ & 314 & $\sim 525$ \\
\hline
\end{tabular}


Sigma) (Mendoza et al. 1992) was used on air-dried spermatozoa smears to trace microscopically acrosomereacted spermatozoa. Cells were incubated with FITC-PSA $\left(6.25 \mu \mathrm{g} / \mathrm{ml}\right.$ in TBS) for $0.5 \mathrm{~h}$, washed with $\mathrm{H}_{2} \mathrm{O}$, and mounted with FluoroGuard Antifade (Bio-Rad Lab).

\section{Data analysis}

Spermatozoa which exhibited green staining over the acrosomal cap were considered as acrosome intact whereas those with only equatorial green staining (i.e. no tri-dimensional green structure) or no staining at all were considered acrosome reacted. A total of three experiments were performed. For each experiment at least 100 cells per slide were evaluated. Acrosome reaction rate was determined by calculating the acrosome reacted spermatozoa/total spermatozoa observed; we then excluded the spontaneous acrosome reaction (AR) rate at the end of capacitation (control without ionophore). The significance of differences between experimental groups was determined by paired t-test. $P<0.01$ was considered significant.

\section{Results}

\section{Calpain 1 and calpain 2 proteins are expressed in mouse spermatozoa}

Western blot analysis was performed using monoclonal antibodies specific for calpain 1 or calpain 2 on extracts of spermatozoa from the cauda epididymis. An $80 \mathrm{kDa}$ band was seen for each isoform (Fig. 1A,B), consistent with the reported molecular mass in somatic cells and in macaque spermatozoa (Yudin et al. 2000). These antibodies were also used for immunofluorescence confocal microscopy to determine the localization of calpain 1 and calpain 2 in mouse spermatozoa. Both calpain 1 and calpain 2 were shown to be localized to the acrosome (Fig. 2A,B).

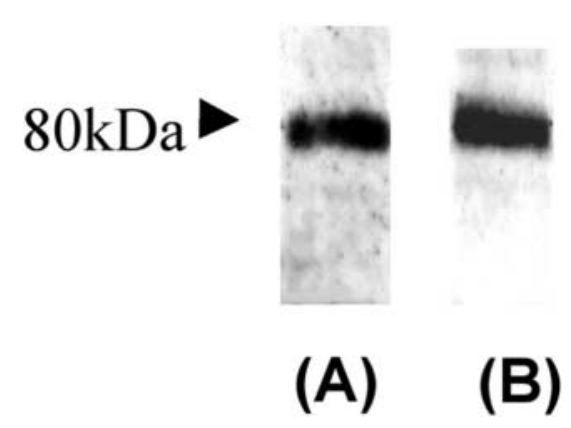

Figure 1 Expression of calpain 1 and calpain 2 in mouse spermatozoa. Sperm proteins were resolved by SDS-PAGE analysis and transferred onto PVDF membrane. The blots were incubated with monoclonal antibodies to either calpain 1 (1:100; A) or calpain 2 (1:100; B), followed by secondary donkey anti mouse antibody $(1: 10000)$ and $\mathrm{ECL}$ detection. The arrow indicates calpain bands at $80 \mathrm{kDa}$, as calculated from the migration of known protein standards.
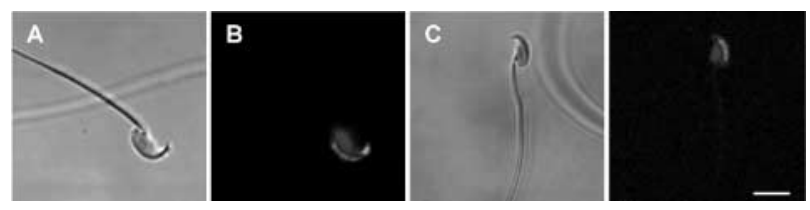

Figure 2 Localization of calpain 1 and calpain 2 in mouse spermatozoa. Cold permeabilized epididymal spermatozoa were labeled with monoclonal antibodies to either calpain $1(1: 75 ; A, B)$ or calpain 2 (1:75; C, D), followed by a Cy3-labeled secondary antibody (1:500). Spermatozoa stained only with secondary antibody and Hoechst served as controls (E, F). The localization of calpain 1 is shown at B and of calpain 2 at D. Phase light micrographs of the same spermatozoa are shown at $\mathrm{A}$ and $\mathrm{C}$. Bar $=10 \mu \mathrm{m}$.

\section{Canp1 and Canp2 mRNAs are present during spermatogenesis}

Using gene-specific primers, RT-PCR generated $189 \mathrm{bp}$ products for Canp1, $163 \mathrm{bp}$ products for Canp2, and 314 bp products for $\beta$-actin (Fig. 3). We had employed the Agilent 2100 Bioanalyzer, a microfluidic system that provides highly reproducible quantification and sizing, which replaces slab gel electrophoresis (Gottwald et al. 2001). This system was used, following the manufacturer's protocol, to analyze the double-stranded cDNA products essentially to replace the need for Northern blotting experiments. Nonetheless, Northern blotting procedures have been employed as well (data not shown). Thus, although the results were concomitant with the RT-PCR results, the signal of the Northern blotting appeared faintly, and therefore could not be used as the sole method. Although it appears visually that Canp1 and Canp2 are expressed at a relatively constant level throughout spermatogenesis, the mean values of three experiments calculated from band densities compared with the $\beta$-actin controls suggested that a minor increase in Canp1 levels occurs during postnatal days 18 to 20 (data not shown).

\section{Calpain 1 and calpain 2 protein expression in adult and juvenile testes}

Immunohistochemistry was used to determine the expression patterns of calpain 1 and calpain 2 in the adult testis. Both isoforms were seen to be expressed throughout spermatogenesis (Fig. 4A,B). However, a higher level of

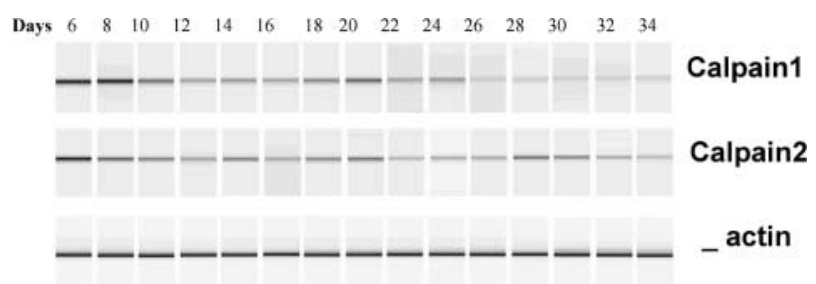

Figure 3 Expression of Canp1 and Canp2 mRNA throughout spermatogenesis. Semi-quantitative RT-PCR amplicons of Canp 1, Canp 2 and $\beta$-actin (control) were detected using the Agilent 2100 instrument. Extracts of total RNA from testes of mice from 6 to 34 days of age served as template for synthesizing first-strand cDNA. 

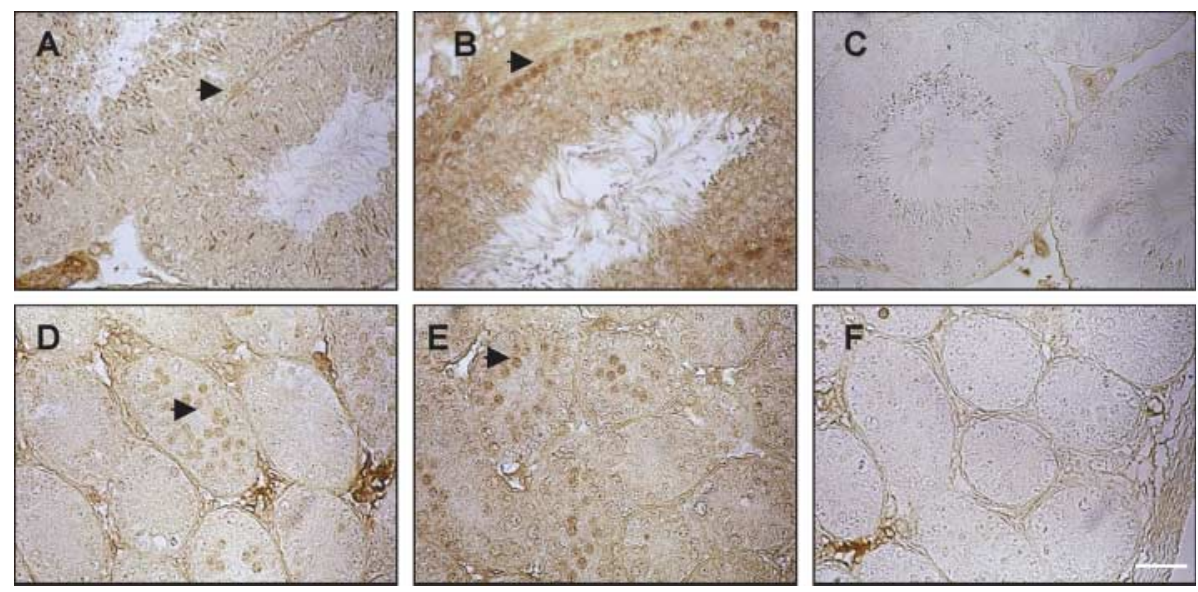

Figure 4 Expression of calpain 1 and calpain 2 in adult and juvenile mice testes. Immunohistochemistry of sections of testes from adult $(\mathrm{A}-\mathrm{C})$ and 10-day-old (C-E) mice was performed using monoclonal antibodies to calpain 1 (1:300; A, D), calpain 2 (1:300; B, E) or no primary antibody $(\mathrm{C}, \mathrm{F})$ followed by peroxidase-labeled secondary antibody and DAB substrate. The arrows point to the intensely stained cells. Bar $=100 \mu \mathrm{m}$. calpain 2 labeling was noted in specific cells at the periphery of the tubule (Fig. 4B). The location and stage of spermatogenesis suggested that these cells were at the beginning of the meiotic phase. To further investigate the meiotic stage, we used immunohistochemistry on testes collected daily from juvenile mice of 6 to 12 days of age. Prior to day 10 , the immunostaining was homogenous. However, on day 10 there was enhanced immunostaining of some cells (Fig. 4E) and on days 11 and 12, the number of strongly stained cells increased. Calpain 1 also showed a slight increase in staining in cells corresponding to zygotene spermatocytes on day 10 (Fig. 4D).

Western blot analysis of lysates from testes isolated at two-day intervals, from day 6 to day 30 after birth, which is already post-pubertal, indicated that total calpain 2 protein levels were relatively uniform as the first wave of spermatogenesis progressed throughout spermatogenesis and spermiogenesis (Fig. 5B). However, the level of calpain 1 protein increased significantly on days 20 and 22

d6 E $101214 \quad 1618202224262830$

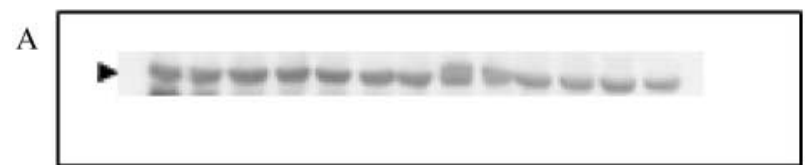

B

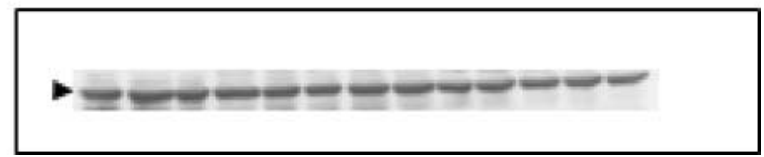

Figure 5 Expression of calpain 1 and calpain 2 throughout spermatogenesis. Testes were collected from 6- to 30-day-old mice. Crude protein extracts were prepared by homogenization in SDS lysis buffer, subjected to PAGE analysis, and transferred onto an Immobilon membrane. The blots were incubated with monoclonal antibody to either calpain 1 (1:100; A) or calpain 2 (1:100; B), followed by ECL detection. The arrows point to bands at $80 \mathrm{kDa}$, as calculated from the migration of known protein standards.
(Fig. 5A), correlating with the increased level of mRNA seen on days 18 and 20.

\section{Effect of calpain inhibitor on the acrosome reaction}

To further explore calpain's possible involvement in the acrosome reaction (AR), we examined the acrosome reaction rate in the presence of several concentrations of the calpain inhibitor, calpeptin. As described in the Materials and Methods section, capacitated spermatozoa were incubated with calpeptin for $10 \mathrm{~min}$ at the end of the capacitation period. They were then exposed to calcium ionophore for $20 \mathrm{~min}$ in the presence of the inhibitor. We used the immunofluorescence method described by Mendoza et al. (1992) to distinguish between acrosomereacted and acrosome-intact spermatozoa, as depicted in Fig. 6A. Inhibition of AR rate was detected in a dosedependent manner. lonophore-induced AR rate reached $33.9 \%$ in the control group (we excluded the spontaneous AR rate at the end of capacitation; Fig. 6B). Calpeptin significantly reduced the $A R$ in a dose-dependent manner, whereas a concentration of $125 \mu \mathrm{M}$ gained the maximal inhibitory effect. The same assay preformed in bovine spermatozoa as a control, produced correlating results to the assay carried out in mice spermatozoa. At a concentration of $125 \mu \mathrm{M}$, calpeptin inhibited the AR rate by $71 \%$ compared with control values (data not shown).

\section{Discussion}

Our study presents, for the first time, an explorative view of calpain ubiquitous isoforms, 1 and 2, beginning with the early course of spermatogenesis to spermatozoa, and leading to fertilization.

In preceding studies performed in rat eggs, we have established a correlation between calpain activation and egg activation at fertilization, while the inhibition of calpain activity hindered resumption of the second meiosis as occurs during fertilization (I Ben-Aharon, $\mathrm{K}$ Haim, $\mathrm{R}$ Shalgi and D Ben-Yosef, unpublished observations). To further explore this facet of calpain in the male germ line we examined the expression pattern of calpain 1 and 
A

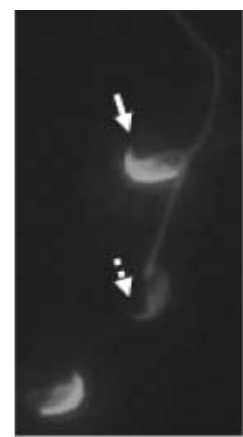

B

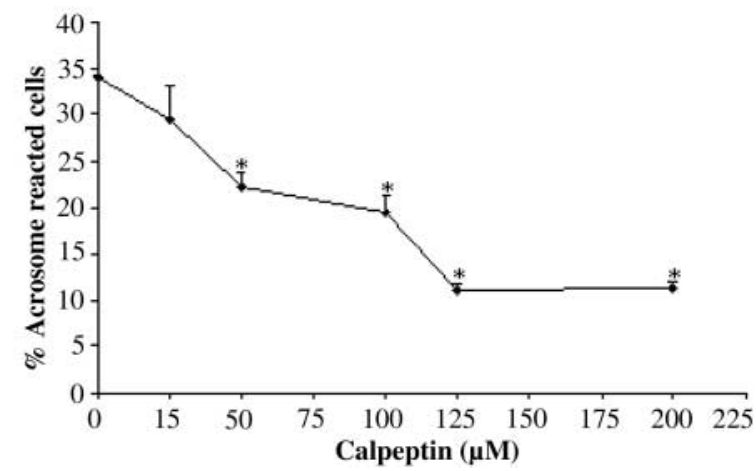

Figure 6 Effect of calpeptin on the acrosome reaction. (A) Acrosomeintact spermatozoa (solid arrow) compared with acrosome-reacted spermatozoa (dashed arrow). (B) Spermatozoa were incubated in $\mathrm{HMB}$ for $1.5 \mathrm{~h}$ to allow capacitation. Calpeptin was added at 25, 50, $100,125,200 \mu \mathrm{M}$ for $10 \mathrm{~min}$ followed by exposure to $10 \mu \mathrm{M}$ A23187 for $20 \mathrm{~min}$. The percentage of acrosome-reacted cells (AR\%) was determined as described in Materials and Methods. The data represent the means \pm S.E. of duplicates from three experiments. $2 \mathrm{mu}^{*}$ $P<0.01$ compared with control.

calpain 2 throughout spermatogenesis. The genomic sequences for Canp1 and Canp2 contain multiple transcription start sites and GC rich regions, features common to housekeeping genes (Hata et al. 1989, Suzuki 1990). Accordingly, we showed that the RNAs for both isoforms are expressed during the whole of spermatogenesis, as expected. This was confirmed by the Western blotting results indicating that both protein isoforms are present in all the phases of the process. Calpain 1 protein levels displayed a slight increase 20 to 22 days after birth. The most advanced germ cells present during this period include late spermatocytes and early spermatids. This period encompasses the first wave of meiotic divisions (Bellvé et al. 1977a). Our results correlate with the up-regulation of Canp1 ( $\mu$ calpain) mRNA levels observed in rat testis during this same period (Sultana et al. 2003). Immunohistochemistry revealed positive staining of calpain 2, as compared with the control, at all cells and also at the Leydig cells, in which both calpains were formerly detected (Sultana et al. 2003). A more distinct staining of calpain 2 was observed at the periphery of the seminiferous tubules. Enhanced cytoplasmic labeling for calpain 2 was also observed in particular cells from the testes of 10day-old mice. The number of intensely stained cells increased during the following two days. Germ cells of the first wave of spermatogenesis enter the meiotic phase around 10 days after birth (Bellvé et al. 1977b). These results may imply the upregulation of calpain 2 expression at the onset of development of primary spermatocytes. However, since this increment was not observed in Western blotting, we cannot rule out the possibility that the intense labeling is due to a conformational change that increases the degree or amount of antibody binding. The potential roles of calpains in mitosis and meiosis and in cell differentiation have already been suggested (Schollmeyer 1988, Malcov et al. 1997, Carafoli \& Molinari 1998) and the present results indicate a possible involvement of calpain at the entry into meiosis.

Previous studies had reported that calpain 1 and calpain 2 are confined to the head of mammalian spermatozoa, either in the acrosomal cap (Schollmeyer 1986, Rojas et al. 1999) or at the outer acrosomal membrane (Yudin et al. 2000). Using confocal immunofluorescence microscopy, we detected both isoforms at the acrosomal cap of the mouse spermatozoa. The acrosome is formed during the early period of spermiogenesis and represents one of the defining features of spermatozoan development. During this process, various proteins are synthesized and incorporated into the acrosome, where they undergo extensive modifications. One of the mechanisms proposed to be involved in these modifications is selective proteolysis, a process that converts an enzymatically inactive precursor form to an enzymatically active mature form (Abou-Haila \& Tulsiani 2000). The localization of calpain 1 and calpain 2 strongly implies their possible participation in the development and function of the acrosome as well.

Aoyama et al. (2001) demonstrated a slight reduction in the acrosome reaction rate of human spermatozoa when inhibiting calpain by the use of calpain inhibitor I, calpain inhibitor II and Z-Leu-Leu-H, which are cysteine proteases inhibitors. To further explore calpain's role in mammalian spermatozoa, we used the selective cell-permeable calpain inhibitor, calpeptin, while performing the assay in bovine spermatozoa as a positive control. Calpeptin significantly impeded acrosome reaction in a dose-dependent manner, as determined by an immunofluorescence assay. Similar inhibition rates were obtained in a control assay performed in bovine spermatozoa.

Cytoskeletal components such as $\alpha$-spectrin, actin and filamin have been localized to the anterior head of mammalian spermatozoa (Yagi \& Paranko 1995, Yudin et al. 2000). These cytoskeletal proteins are known to have undergone remodeling by calpain in many cell types (Potter et al. 1998, Spira et al. 2003). Actin filament breakdown represents a key regulatory pathway, in which calpain may participate as a potential participator in the process, as previously known from other cell types (Carragher \& Frame 2002). Diverse cytoskeletal remodeling such as actin filament breakdown, also occurs during the cascade of events leading to membrane fusion through the 
acrosome reaction (Breitbart 2002, Brener et al. 2003). In order to study calpain's possible role during fertilization, we also performed an in vitro fertilization assay in rats while exposing the gametes to calpeptin. Fertilization rate was drastically reduced compared with controls (I BenAharon, K Haim, R Shalgi and D Ben-Yosef, unpublished observations). Using calpain inhibitors, Rojas and MorettiRojas (2000) demonstrated a reduced sperm-egg fusion rate in zona-free hamster eggs and the human spermatozoa system. Thus, our results may imply that calpain has a role in the calcium-mediated processes involving membrane fusion i.e. the acrosome reaction and/or sperm-egg fusion at fertilization.

There is some evidence suggesting that $\mathrm{Ca}^{2+}$ is involved in processes that occur during the development of spermatozoa and their function. Furthermore, it has been well documented that calcium is a key player in the cascade of events leading to successful fertilization. Since calpains, the $\mathrm{Ca}^{2+}$-dependent cysteine proteases, are pluripotential with numerous substrates, it is possible that they may serve as effectors in more than one pathway in the intricate process of spermatogenesis and the functioning of the mature spermatozoa.

\section{Acknowledgements}

We thank Hassida Orenstein for her skilful technical assistance and Dr Leonid Mittelman for his useful assistance with the confocal microscopy. The authors declare that there is no conflict of interest that would affect the impartiality of this scientific work.

\section{References}

Abou-Haila A \& Tulsiani DR 2000 Mammalian sperm acrosome: formation, contents, and function. Archives of Biochemistry and Biophysics 379 173-182.

Aoyama T, Ozaki Y, Aoki K, Kunimatsu M, Tada T, Sasaki M \& Suzumori K 2001 Involvement of mu-calpain in human sperm capacitation for fertilization. American Journal of Reprod Immunol $4512-20$.

Arthur JS, Elce JS, Hegadorn C, Williams K \& Greer PA 2000 Disruption of the murine calpain small subunit gene, Capn4: calpain is essential for embryonic development but not for cell growth and division. Molecular Cell Biology 20 4474-4481.

Bailey JL \& Storey BT 1994 Calcium influx into mouse spermatozoa activated by solubilized mouse zona pellucida, monitored with the calcium fluorescent indicator, fluo-3. Inhibition of the influx by three inhibitors of the zona pellucida-induced acrosome reaction: tyrphostin A48, pertussis toxin, and 3-quinuclidinyl benzilate. Molecular Reproduction and Development 39 297-308.

Barnoy S, Zipser Y, Glaser T, Grimberg Y \& Kosower NS 1999 Association of calpain $\left(\mathrm{Ca}^{2+}\right.$-dependent thiol protease) with its endogenous inhibitor calpastatin in myoblasts. Journal of Cellular Biochemistry 74 522-531.

Bellvé AR, Millette CF, Bhatnagar YM \& O'Brien DA 1977a Dissociation of the mouse testis and characterization of isolated spermatogenic cells. Journal of Histochemistry and Cytochemistry 25 480-494.

Bellvé AR, Cavicchia JC, Millette CF, O'Brien DA, Bhatnagar YM \& Dym M $1977 b$ Spermatogenic cells of the prepuberal mouse. Isolation and morphological characterization. Journal of Cell Biology 74 68-85.
Berrios J, Osses N, Opazo C, Arenas G, Mercado L, Benos DJ \& Reyes JG 1998 Intracellular $\mathrm{Ca}^{2+}$ homeostasis in rat round spermatids. Biology of the Cell 90 391-398.

Breitbart H 2002 Intracellular calcium regulation in sperm capacitation and acrosomal reaction. Molecular and Cellular Endocrinology 22 139-144.

Brener E, Rubinstein S, Cohen G, Shternall K, Rivlin J \& Breitbart H 2003 Remodeling of the actin cytoskeleton during mammalian sperm capacitation and acrosome reaction. Biology of Reproduction 68 837-845.

Carafoli E \& Molinari M 1998 Calpain: a protease in search of a function? Biochemical and Biophysical Research Communications 247 193-203.

Carragher NO \& Frame MC 2002 Calpain: a role in cell transformation and migration. International Journal of Biochemistry and Cell Biology 34 1539-1543.

Croall DE \& DeMartino GN 1991 Calcium-activated neutral protease (calpain) system: structure, function, and regulation. Physiological Reviews 71 813-847.

Gottwald E, Muller O \& Polten A 2001 Semiquantitative reverse transcription-polymerase chain reaction with the Agilent 2100 Bioanalyzer. Electrophoresis 22 4016-4022.

Hagiwara S \& Kawa K 1984 Calcium and potassium currents in spermatogenic cells dissociated from rat seminiferous tubule. Journal of Physiology 356 135-149.

Hata A, Ohno S, Akita Y \& Suzuki K 1989 Tandemly reiterated negative enhancer-like elements regulate transcription of a human gene for the large subunit of calcium-dependent protease. Journal of Biological Chemistry 264 6404-6411.

Jones R, Brown CR, Cran DG \& Gaunt SJ 1983 Surface and internal antigens of rat spermatozoa distinguished using monoclonal antibodies. Gamete Research 8 255-265.

Kalab P, Visconti P, Leclerc P \& Kopf GS 1994 p95, the major phosphotyrosine-containing protein in mouse spermatozoa, is a hexokinase with unique properties. Journal of Biological Chemistry 269 3810-3817.

Kline D \& Kline JT 1992 Repetitive calcium transients and the role of calcium in exocytosis and cell cycle activation in the mouse egg. Developmental Biology 149 80-89.

Laemmli UK 1970 Cleavage of structural proteins during assembly of the head of bacteriophage T4. Nature 227 680-685.

Lane RD, Allan DM \& Mellgren RL 1992 A comparison of the intracellular distribution of mu-calpain, m-calpain, and calpastatin in proliferating human A431 cells. Experimental Cell Research 203 5-16.

Malcov M, Ben-Yosef D, Glaser T \& Shalgi R 1997 Changes in calpain during meiosis in the rat egg. Molecular Reproduction and Development 48 119-126.

Mendoza C, Carreras A, Moos J \& Tesarik J 1992 Distinction between true acrosome reaction and degenerative acrosome loss by a one-step staining method using Pisum sativum agglutinin. Journal of Reproduction and Fertility 95 755-763.

Murachi T 1989 Intracellular regulatory system involving calpain and calpastatin. Biochemistry International 18 263-294.

Perrin BJ \& Huttenlocher A 2002 Calpain. International Journal of Biochemistry and Cell Biology 34 722-725.

Potter DA, Tirnauer JS, Janssen R, Croall DE, Hughes CN, Fiacco KA, Mier JW, Maki M \& Herman IM 1998 Calpain regulates actin remodeling during cell spreading. Journal of Cell Biology 141 647-662.

Rojas FJ \& Moretti-Rojas I 2000 Involvement of the calcium-specific protease, calpain, in the fertilizing capacity of human spermatozoa. International Journal of Andrology 23 163-168.

Rojas FJ, Brush M \& Moretti-Rojas I 1999 Calpain-calpastatin: a novel, complete calcium-dependent protease system in human spermatozoa. Molecular Human Reproduction 5 520-526.

Sagata N, Watanabe N, Vande-Woude GF \& Ikawa Y 1989 The c-mos proto-oncogene product is a cytostatic factor responsible for meiotic arrest in vertebrate eggs. Nature 342 512-518. 
Santella L, Kyozuka K, De Riso L \& Carafoli E 1998 Calcium, protease action, and the regulation of the cell cycle. Cell Calcium $\mathbf{2 3}$ $123-130$

Santella L, Kyozuka K, Hoving S, Munchbach M, Quadroni $M$, Dainese P, Zamparelli C, James P \& Carafoli E 2000 Breakdown of cytoskeletal proteins during meiosis of starfish oocytes and proteolysis induced by calpain. Experimental Cell Research 259 $117-126$

Santi CM, Santos T, Hernandez-Cruz A \& Darszon A 1998 Properties of a novel $\mathrm{pH}$-dependent $\mathrm{Ca}^{2+}$ permeation pathway present in male germ cells with possible roles in spermatogenesis and mature sperm function. Journal of General Physiology $11233-53$.

Schollmeyer JE 1986 Identification of calpain II in porcine sperm. Biology of Reproduction 34 721-731.

Schollmeyer JE 1988 Calpain II involvement in mitosis. Science $\mathbf{2 4 0}$ 911-913.

Slaughter GR, Meistrich ML \& Means AR 1989 Expression of RNAs for calmodulin, actins, and tubulins in rat testis cells. Biology of Reproduction 40 395-405.

Sorimachi H, Ishiura S \& Suzuki KA 1993a Novel tissue-specific calpain species expressed predominantly in the stomach comprises two alternative splicing products with and without $\mathrm{Ca}^{2+}$-binding domain. Journal of Biological Chemistry 268 19476-19482.

Sorimachi H, Toyama-Sorimachi N, Saido TC, Kawasaki H, Sugita H, Miyasaka M, Arahata K, Ishiura S \& Suzuki K 1993b Musclespecific calpain, p94, is degraded by autolysis immediately after translation, resulting in disappearance from muscle. Journal of Biological Chemistry 268 10593-10605.

Sorimachi H, Saido TC \& Suzuki K 1994 New era of calpain research. Discovery of tissue-specific calpains. FEBS Letters 343 $1-5$.

Spira ME, Oren R, Dormann A \& Gitler D 2003 Critical calpaindependent ultrastructural alterations underlie the transformation of an axonal segment into a growth cone after axotomy of cultured Aplysia neurons. Journal of Comparative Neurology 457 293-312.

Sultana T, Wahab-Wahlgren A, Assmus M, Parvinen M, Weber G \& Soder O 2003 Expression and regulation of the prointerleukin-1 alpha processing enzymes calpain I and II in the rat testis. International Journal of Andrology 26 37-45.

Suzuki K 1990 The structure of calpains and the calpain gene. In Intracellular calcium-dependent proteolysis. pp 25-35. Eds RL Mellgren \& T Murachi. Boca Raton, FL: CRC Press.

Towbin H, Staehelin T \& Gordon J 1979 Electrophoretic transfer of proteins from polyacrylamide gels to nitrocellulose sheets: procedure and some applications. PNAS 76 4350-4354.

Visconti PE, Bailey JL, Moore GD, Pan D, Olds-Clarke P \& Kopf GS 1995 Capacitation of mouse spermatozoa. I. Correlation between the capacitation state and protein tyrosine phosphorylation. Development 121 1129-1137.

Watanabe N, Vande-Woude GF, Ikawa Y \& Sagata N 1989 Specific proteolysis of the c-mos proto-oncogene product by calpain on fertilization of Xenopus eggs. Nature 342 505-511.

Watanabe D, Yamada K, Nishina Y, Tajima Y, Koshimizu U, Nagata A \& Nishimune $\mathbf{Y} 1994$ Molecular cloning of a novel $\mathrm{Ca}^{2+}$-binding protein (calmegin) specifically expressed during male meiotic germ cell development. Journal of Biological Chemistry 269 7744-7749.

Whitaker M \& Patel R 1990 Calcium and cell cycle control. Development 108 525-542.

Yagi A \& Paranko J 1995 Actin, alpha-actinin, and spectrin with specific associations with the postacrosomal and acrosomal domains of bovine spermatozoa. Anatomical Record 241 77-87.

Yanagimachi R 1989 Sperm capacitation and gamete interaction. Journal of Reproduction and Fertility $\mathbf{3 8}$ (Suppl) 27-33.

Yudin AI, Goldberg E, Robertson KR \& Overstreet JW 2000 Calpain and calpastatin are located between the plasma membrane and outer acrosomal membrane of cynomolgus macaque spermatozoa. Journal of Andrology 21 721-729.

Received 28 March 2004

First decision 20 May 2004

Revised manuscript received 10 October 2004

Accepted 29 November 2004 